\title{
The Level of ICT Infrastructure as a Factor of ICT Integration in Greek High School Science Teaching
}

\author{
Charalampos Apostolou \\ High school science teacher, $3^{\text {rd }}$ Gymnasium of Kozani, Greece \\ bob.apostolou@gmail.com \\ DOI: 10.34190/JEL.18.6.008
}

\begin{abstract}
This paper examines the extent to which the level of technological equipment affects the integration of the Information and Communication Technologies (ICT) in Greek high school science teaching. The limited ICT infrastructure environment, with only one computer-projector system available and access to the internet ("PC-VP" environment), is compared to the high level ICT environment ("1:1" environment) where, in addition to the computer-projector system, each student has access to a computer and the internet. It is a study relying on a relatively small dataset derived from student answers to a questionnaire aiming to determine the degree to which some of the "expected" ICT benefits reach the students. The level of ICT integration is judged by the degree to which the ICT benefits reach the students. That is, the more the ICT benefits reach the students, the better - or the greater - the ICT integration is. The participants were eightynine, 14-year-old students who belonged in four different classes and the teacher who taught Physics in those classes. The SPSS non-parametric "Man-Whitney U Test" test was used to compare the statistical distributions of student answers. The results show that, when the applied teaching approach is used, the ICT integration is equally successful in both environments. This questions the idea of investing in "1:1" environments in the Greek public schools where less student centered and inquiry oriented teaching approaches are the norm. It also highlights the importance of the specific teaching approach as an ICT integration tool in "PC-VP" environments that still exist in most Greek schools.
\end{abstract}

Keywords: ICT integration, ICT infrastructure, high school science teaching

\section{Introduction}

The Information and Communication Technologies (ICT) have dramatically changed the way we live and have opened new horizons in nearly every sector of our society. However, despite their great potential, the ICT integration in the daily teaching practice is not an easy task (Osborne \& Hennessy, 2003; Penuel, 2006; Unal and Ozturk HI, 2012; Platinakis, 2011; Tzifopoulos, 2010; Flores, Santero and Gordillo, 2017). As far as it concerns the secondary education public schools of Greece, even today, the most important obstacle to the ICT integration is the lack of basic technological infrastructure in the classroom. In February 2020, the mapping of the existing ICT infrastructure by the Regional Directorate of Education of Western Macedonia - which is a region in the north-western part of Greece - showed that, the majority of classrooms in the secondary education schools lacked the basic ICT equipment for any ICT integration. That is, in most classrooms, a computer-video projector system was not present. Since the infrastructure of the Greek schools is mainly provided through nationwide programs by the Ministry of Education, the same situation is expected to be the case for the other twelve (12) Regional Directorates (educational districts) of the country. This means that even today the lack of ICT infrastructure is a significant obstacle to ICT integration for most of the Greek public high school teachers. The Greek Ministry of Education (YПAІӨ) has been trying to upgrade the technological infrastructure of Greek schools through European Union programs (European Commission, 2019) and so far has managed to supply several school classrooms with video-projectors and to connect schools to the internet via broadband lines.. However, taking into account the current financial situation, the installation of a computer-video projector system in every school classroom is probably the best thing we can expect to happen, in the next couple years.

Hew and Brush (2007) in a summary of previous empirical studies showed that in descending order of relative frequency, the most frequently reported category of barriers to ICT integration is "Resources" at $40 \%$ frequency, followed by "Knowledge / Skills" at 23\% frequency. The "Resources" category mainly includes the available ICT infrastructure (e.g. access to computers, video projectors, printers, etc.). Experimental studies conducted in Greece (Platinakis,, 2011) show that the obstacles reported by Greek teachers in the Greek High School are similar to those reported in the international literature. Several more studies suggest that the ICT infrastructure available in the classroom has always been essential to effectively embed ICT in teaching and learning (Bariu, 2020; Hyunjin,Taejung and Jongwon, 2020; Lu,Tsai and Wu, 2015; Voogt et al., 2013). However, those studies do not examine the degree to which specific levels of "Resources" may affect ICT integration. Furthermore, there seems to be an absence of studies concerning the benefits of ICT integration 
in environments of limited ICT infrastructure such as the "PC-VP" environment as described in the next paragraph. In this context, this paper comes to explore the extent to which two different levels of technological infrastructure ("PC-VP" and "1:1") as described here, can affect the level of ICT integration. Here, the level of ICT integration is judged by the degree to which the expected ICT benefits reach the students.

Obviously, in order to use technology (ICT) in the classroom, some elementary level of ICT infrastructure is required; otherwise there can be no use of any digital material. We consider this elementary level to be a computer - video projector system with access to the internet. This system is the only ICT infrastructure available in the classroom and is mainly used for presentation purposes mainly by the teacher and occasionally by the students. From now on, this environment will be called "PC-VP" environment. On the opposite side, there is the "high level" of infrastructure where each student has direct and continuous access to a computer and to the internet and where a computer - video projector system is also available for the teacher or the students to use. This environment will henceforth be called the "1:1" environment. The main question this paper aims to answer is: "How does the level of ICT integration compares in these two ICT infrastructure environments (PC-VP and 1:1)?"

The way teachers use technology in the classroom is one of the most important factors for the success of the ICT integration. Norris and Elliot (2010) reported that this was the main factor or reason for the failure of several 1:1 programs in USA schools. In this light, "the way the ICT was used" (the teaching approach or practice) by the teacher who participated in this study, is an important factor which can affect the attempted ICT integration and for this reason it is described in a separate section. The integration of ICT in both environments (PC-VP and 1:1) was implemented through the same teaching approach.

The answer to "how much or what technological equipment is necessary for the ICT benefits to reach the students" is of great value to those who provide or decide for the infrastructure of public schools (State, School Committees, Parents' associations, etc.). It goes without saying that providing for "1:1" environment infrastructure, besides the cost of the equipment, also requires continuous computer maintenance, technical support, familiarization of students with software and computer operation and management of computer storage and security. In other words, it requires significantly more resources than just implementing "PC-VP" environment infrastructure and this should be taken into account.

\subsection{The ICT benefits for Science teaching}

The potential contribution of technology use - or ICT integration - to science teaching and learning has been reported in previous studies (Osborne \& Hennessy, 2003; Hennessy, Deaney and Ruthven, 2004; Drayton et al., 2010) and can be summarized in the following eight (8) benefits:

1. They can improve student motivation and engagement.

2. By providing access to experiences not otherwise feasible and by linking school science teaching to real life phenomena and to contemporary science, they can make teaching more interesting to students.

3. By providing visualization and multiple representations of physical processes and phenomena, they can enhance understanding.

4. By providing parametric simulations and by facilitating the calculation of data, they provide more opportunities for student participation in inquiry activities.

5. They can facilitate exploration and experimentation by providing immediate visual feedback.

6. They can foster collaborative learning by providing more opportunities for collaboration.

7. They can make student work possible in conditions or environments that are not possible in the actual school laboratory, such as environments without gravity or friction.

8. They can make student work more productive by saving teaching time from time-consuming manual processes such as data management and graph construction to the benefit of reflection, discussion and interpretation.

This paper explores the extent to which these benefits reach students in the two different ICT infrastructure environments when the teaching practice - as described below - is applied.

We should realize that those are potential benefits and that infrastructure alone is insufficient for effective ICT integration into the classroom (Flores, Santero and Gordillo, 2017). In other words, putting computers in classrooms is not always beneficial for teaching and learning and that the resulting benefit depends mainly on what teachers do in classrooms (Cuban, 2006; Norris \& Elliot, 2010; Flores, Santero and Gordillo, 2017). There 
are studies showing that the use of computers in the classroom has a positive effect on student learning (Bebell, 2005; Penuel, 2006; Zucker \& McGhee, 2005; Gulek \& Demirtas, 2005; Dunleavy \& Heinecke, 2007) however there are also studies showing that the benefit may not be such as to justify the required time and money investment (Osborne \& Hennessy, 2003; Cuban, 2006; Hu, 2007; Stanbury, 2010; Norris \& Elliot, 2010; Sauers \& Scott, 2012).

\subsection{The applied teaching practice}

The same teaching approach was applied throughout the school year, in both environments (PC-VP and 1:1) and in both cases, Digital Work Sheets (DWS) were used. In "1:1" environment, students read them, scroll through them and type their answers to the DWS questions in their computer. In "PC-VP" environment, the DWS are displayed in a large screen (on the board) and students write their answers in their notebook. In both environments the same worksheets were used. Students were organized in 2-member teams (one team per student desk) and collaborated for the completion of each activity contained in the DWS.

The DWS are MS-Word files (.docx files) and therefore have the "capabilities" of the "MS-Word" application by which they were created. That is, in addition to text, through their hyperlinks they can "contain" any form and amount of digital content, such as videos, simulations, virtual labs, quizzes or any other digital content available on the Internet. In this sense they can be "interactive". In the "1:1" environment, the students themselves can access the material of the hyperlinks at will, while in the "PC-VP" environment, this material is accessed by the teacher. The specific DWS are characterized by limited text for the benefit of other forms of teaching material such as images, videos, simulations and virtual labs. This makes DWSs more attractive and increases student participation. Also, hyperlinks are mainly placed in images - not in text. This urges students to "click" on them in order to see what comes after the "click".

The implemented teaching approach adopts inquiry practices as well as elements of the constructivist approach. By "inquiry practices" we refer to practices students use when they get involved in studentcentered, hands-on activities with discovery (Smallhorn et al., 2015). The teacher acts mainly as a facilitator providing guidance during a learning activity and promoting student discussion - mainly a whole class discussion in our case. These practices are described as "Practices for K-12 Science classrooms" by the (United States) National Research Council (2012) and include: 1. Asking questions, 2. Developing and using models, 3. Planning and carrying out investigations, 4. Analyzing and interpreting data, 5. Using mathematics and computational thinking, 6. Constructing explanations, 7. Engaging in argument from evidence, 8. Obtaining, evaluating, and communicating information. These practices are implemented either through the work of students in teams, or through whole class discussion. The work of the students is usually guided by the DWS. That is, the teaching in most cases takes the form of guided-inquiry based learning. However, when the inquiry takes place in whole class discussion, which is directed by the teacher, it may also take the form of open -inquiry based learning. "Elements of the constructivist approach" means that students themselves construct their knowledge through a process that involves change (Olsen, 1999). Communication, negotiation, cooperation, reflection, and discussion reciprocity are qualities of Constructivist approach (Karal, Bahçekapılı and Reisoglu, 2009). Constructivist activities empower the learners to gain access to their experiences and beliefs that reshape their prior knowledge in the light of the applied course content (Nuket and Cigdem, 2014). The new knowledge has to come through experience of new authentic situations provided by the student activities in class and builds on students' prior knowledge, "connects" with it and possibly reorganizes it. For this, students must have an active role in teaching. Inquiry-based learning provides suitable ground for student to construct their knowledge i.e. for constuctivistic didactic approaches. Eliciting prior knowledge, creating cognitive dissonance, application of new knowledge with feedback, and reflection on learning, are essential features of constructivism (Baviskar, Hartle, and Whitney, 2009). These features were taken into account in our teaching approach.

Usually, in the beginning of a student activity, students are asked to make predictions or formulate explanations-interpretations of phenomena or processes that are related to their experiences. This way, the student ideas-preconceptions are recorded (a characteristic of a constructive approach). Students are then given the opportunity to explore the validity of their predictions and explanations through a variety of exploratory activities. These may include performing real or virtual experiments, using information from the Internet and discussing and arguing with each other in their teams. The DWS activities require exploration practices such as formulating questions, designing experiments, studying texts, collecting and managing experimental data, using arguments, interpreting results, and presenting findings-conclusions. Where possible, 
at the end of the activity students are asked to compare their initial views with the conclusions they have reached (also characteristic of a constructive approach). At the end of each activity there is an open whole class discussion where - with the guidance of the teacher - the conclusions of the teams are discussed and the class ends up with commonly accepted conclusions. Because the whole class discussion is a key element of the applied teaching approach, most student activities are short in time in order to allow for more such discussions during a class session.

To better understand the teaching approach applied, a student activity in Physics of the 3rd Grade or C Class (age 14) in Lower Secondary School (Gymnasium) is described. The subject is "Sound waves":

First, the teacher asks the class "why many animals hear sounds that we cannot hear". In an open discussion all possible student explanations are heard and recorded. This is followed by individual student work which includes a) a visit to the Wikipedia website (https://el.wikipedia.org/wiki/Akoń) to study the text of the paragraph "The way we hear" and b) watching a video showing the effect of frequency on the oscillation of a membrane. In the video, there is a ruler that plays the role of the ear drum membrane that oscillates at different frequencies when a sound wave reaches it. After their individual work, students work together in their team in order to answer the original question. At this stage, they formulate and evaluate opinions and use arguments in order to come to a common conclusion. After their collaboration, the teams present their conclusions in a whole class discussion which is coordinated by the teacher. Through this discussion, the final and commonly accepted conclusions emerge. At the end of the activity, the final conclusions are compared with the initial student views-explanations.

\section{Method}

\subsection{Data collection methodology}

The study draws data from four 3rd Grade classes (C classes) of the $3^{\text {rd }}$ Gymnasium of the City of Kozani, and extends into two consecutive school years, 2011-12 and 2012-13. The School is a typical public school in the city of Kozani and during this research it had 12 classes distributed in three grades (A, B and C Classes). That is, there were 3 classes per grade, with 20-25 students in each class.

In the following text as well as in the tables and pictures of this article, there are references to specific classes. The expression "class-school-year" is used for their coding. For example, the symbolism "C-3gym-2012" means the "Class C of the 3rd Gymnasium, in the year 2012".

The participants are eighty-nine (89) students from the four (4) different participating classes and the teacher who taught in those classes. Two of those classes were C Classes during the school year 2011-12 (C-3gym2012) while the other two were C Classes during the next school year 2012-13 (C-3gym-2013). The subject taught in all classes was Physics. The teacher who taught the classes had 20 years of teaching experience in secondary education and was a certified teacher in the "B level" training program which concerns the use of ICT in teaching practice.

The DWS were used in "PC-VP" and "1:1" environments. The "1:1" environment was possible in the Greek public high school because the Greek Ministry of Education, through the "Digital Classroom" program - a program funded by the European Union - provided all first grade Greek students with laptops - the so-called "student netbooks". This happened in October 2009 and enabled the creation of "1:1" teaching environments for grades A, B and C of high schools during the school years 2009-10, 2010-11 and 2011-12 respectively. Class "C-3gym-2012" from which data for the "1:1" environment are drawn, is such a class. The following year (2013), "1:1" environment was not possible for the C class and for this reason this class the "C-3gym-2013" class was taught in a "PC-VP" environment. The data for the "PC-VP" environment come from class C-3gym2013.

The data presented in this paper come from the students' answers to a questionnaire given to them at the end of each school year. This insured students had enough time to form an opinion about the benefits of the ICT integration in class. The questionnaire was the only possible way of collecting data by the teacher. For this, there was no need for any approval since the students were asked to answer questions concerning the quality of a new teaching method with the purpose of improving it. The effect of the different level of maturity of the 
compared classes was examined and the results showed that age affects the effectiveness of the ICT integration. However this is beyond the scope of this study and for this reason is not presented here.

For the answers, a Likert scale was used with five possible options. The questionnaire was answered anonymously. Before completing the questionnaire, students were asked to compare the teaching with DWS with the teaching in other subjects where there wasn't any ICT integration.

In order to investigate the effect of the ICT infrastructure on the ICT integration, the data obtained from the two "C-3gym-2013" classes which were taught in the 1:1 environment, are compared with the data obtained from the two "C-3gym-2012" classes, which were taught in the PC-VP environment. For the compared C-3gym2013 and C-3gym-2012 classes, the parameters "teacher", "school", "science subject" and "student age" that could also affect the ICT integration are the same. The only parameter (variable) that is different between those classes and that could affect the ICT integration is the "ICT environment" which is the focus of this study.

The questionnaire was self-developed and contained eight (8) questions which were created based on the eight (8) ICT benefits to Science teaching, which were mentioned in the previous section. For each benefit, one or two questions were created asking students to say whether they were recipients of this specific benefit. Thus, eight (8) questions were created which correspond to the first seven (7) ICT benefits. For the eighth (last) benefit questions were not created because it was considered that this benefit could not be perceived by the students. The reasoning was that the more the ICT benefits reach the students, the better - or the greater the ICT integration is.

The eight questions students were asked to answer were:

1. Q.13: To what extent do you agree with the sentence "Now I understand the lesson better"?

2. Q.31: To what extent did the lesson become more interesting because it contains multimedia material (videos, simulations and virtual experiments)?

3. Q.33: To what extent did the use of ICT increase your engagement/participation in class?

4. Q.34: To what extent do you think the use of ICT linked Physics to real life?

5. Q.35: To what extent did the use of ICT provide more opportunities for inquiry and reflection?

6. Q.36: To what extent do you think the use of ICT provided more opportunities for collaboration in class?

7. Q.44: To what extent do you think the use of ICT provided more opportunities to check the effect of variables when working with multivariable experiments?

8. Q.45: To what extent do you think the use of ICT provided more opportunities to perform experiments in conditions not possible in the school laboratory?

"Table 1" shows the benefit to which each question corresponds. In Table 1, the questions are not numbered consecutively, but rather as Q13/31/33/34/35/36/44/45. To avoid any confusion, we need to say that these questions were part of a larger question database which also included questions investigating other matters such as the operational state of the notebooks in the 1:1 environment or some of the difficulties the students could have faced while working in such an environment.

Table1: Matching the questions with the ICT benefits

\begin{tabular}{|c|c|}
\hline Question & Benefit \\
\hline Q.33 & 1. They can improve student motivation and engagement. \\
\hline $\begin{array}{l}\text { Q.31 } \\
\text { and } \\
\text { Q.34 }\end{array}$ & $\begin{array}{l}\text { 2. By providing access to experiences not otherwise feasible and by linking school science teaching to real } \\
\text { life phenomena and to contemporary science, they can make teaching more interesting to students. }\end{array}$ \\
\hline Q.13 & $\begin{array}{l}\text { 3. By providing visualization and multiple representations of physical processes and phenomena, they can } \\
\text { enhance understanding. }\end{array}$ \\
\hline Q.44 & $\begin{array}{l}\text { 4. By providing parametric simulations and by facilitating the calculation of data, they provide more } \\
\text { opportunities for student participation in inquiry activities. }\end{array}$ \\
\hline Q.35 & 5. They can facilitate exploration and experimentation by providing immediate visual feedback. \\
\hline Q.36 & 6. They can foster collaborative learning by providing more opportunities for collaboration. \\
\hline Q.45 & $\begin{array}{l}\text { 7. They can make student work possible in conditions or environments that are not possible in the actual } \\
\text { school laboratory, such as environments without gravity or friction. }\end{array}$ \\
\hline
\end{tabular}


The results came from the students' answers to the eight questions shown in Table 1. Forty-eight (48) students who were taught in a "PC-VP" environment and forty-one (41) students who were taught in a "1:1" environment answered those questions. When students answer "Significantly", "A lot" or "Very much" to a specific question, then the specific corresponding benefit is considered to have reached the students at a satisfactory degree. This criterion was used to assess the degree to which the ICT benefits reached the students through these two ICT environments (PC-VP and 1:1).

The following should be taken into consideration:

More data comparing ICT integration in PC-VP and 1:1 environments could not be collected in the following years (since 2013) because 1:1 environments did not exist in the schools where the participant Teacher was teaching. Up to this day, no considerable further improvement in the ICT infrastructure of the daily secondary Greek school classrooms has taken place since the year 2013. The publishing of this research has been delayed in the hope of getting more data. Due to the limited amount of data we consider it to be a preliminary study.

As already mentioned earlier (in Introduction), even today (Feb. 2020), the majority of the secondary education public school classrooms lack the basic ICT equipment for any ICT integration which is a computervideo projector system. For this reason, teachers who are lucky to teach in PC-VP classrooms and want to use ICT in their teaching should plan their instruction for this environment (PC-VP). This was another reason to publish this overdue - since the data collection - study. The financial situation in Greece is more or less the same compared to what it was in 2011-13 and the same challenges concerning educational investment are still in place. The coronavirus pandemic has made things even worse in the current year. However, there are European Union programs running, though which there is a good prospect of improving the public school ICT infrastructure.

\subsection{Data analysis methodology}

The SPSS application (v. 19) was used for the statistical analysis of data. The non-parametric "Man-Whitney U Test" test was used to compare the statistical distributions of student answers. This test was chosen because students' possible choices (answers) were very limited (only 5). With the same software, the statistical measures (Mean and Standard Deviation) were calculated. The "Man-Whitney U Test" test was used to compare the statistical distributions that do not exhibit normal distribution. This is the case either when the amount of data is a limited or when the values the parameter in question can take are limited or when both of these conditions happen simultaneously. In our case, both, the compared samples are small ( $\mathrm{N}=62$ and $\mathrm{N}=48$ for $A$ and $C$ classes) and the possible values for the compared parameter (the answer to a specific ICT benefit) are only five (from 1 to 5). Had the compared distributions exhibited normal distribution, the "T-test" would have been used because it produces relatively more reliable results.

To estimate the degree to which a) the lower Secondary school students (ages 12-14) can meaningfully form an opinion about the "enjoyment" and the "understandability" of teaching (lesson) and b) the questions used could detect any differences in student answers caused by a change of some factor which might affect the student answers, we compared the answers of two student groups of different age. If the age factor actually affects student answers and the comparison of student answers to those two questions shows considerable difference, then it is most likely that a) the students can meaningfully form an opinion about what they are asked by the questions, and b) the questions are a proper tool to detect differences in student answers. In a way, this comparison could play the role of a pilot test in this study. The two student groups compared for this purpose were the A Class $(\mathrm{N}=62)$ and $C$ Class $(\mathrm{N}=48)$ students, ages 12 and 14 respectively who were taught in PC-VP environment, the same subject, by the same teacher. The only factor left to affect student answers was the age factor. For the comparison of the statistical distributions of the student answers the Mann-Whitney Test was used. The results are shown in Table 2. 
Table 2: Statistic comparisons \& measures of student answers for A \& C Classes in "PC-VP" environment

\begin{tabular}{|c|c|c|c|}
\hline Question & $\begin{array}{c}\text { Compairing: } \\
\text { A Class } \\
\text { \& } \\
\text { C Class } \\
\text { Z / Sig }\end{array}$ & $\begin{array}{l}\text { Means: } \\
\text { A Class } \\
\text { C Class }\end{array}$ & $\begin{array}{c}\text { St. Deviations } \\
\text { A Class } \\
\text { / } \\
\text { C Class }\end{array}$ \\
\hline $\begin{array}{l}\text { To what extent did the lesson become more } \\
\text { interesting? }\end{array}$ & $3,876 / 0,000$ & $4,60 / 3,85$ & $0,664 / 1,185$ \\
\hline $\begin{array}{l}\text { To what extent do you agree with the sentence "Now I } \\
\text { understand the lesson better"? }\end{array}$ & $2,346 / 0,019$ & 4,47 / 4,00 & $0,671 / 1,031$ \\
\hline
\end{tabular}

Judging from the Sig values $(<<0.05)$ in Table 2, we can say that at "95\% confidence level" ( $p>0.05)$, for both questions, there is statistically significant difference in the student answers for the " $A$ " and " $C$ " Classes. This suggests the questionnaire used in this study can "detect" factors affecting the ICT integration and thus it can be used as a tool for this purpose.

\section{Results}

The student answers are presented in the form of diagrams (Figures 1 and 2). "Figure 1" presents the statistical distribution of the answers of the student who were taught in a "PC-VP" environment, while "Figure 2" presents the answers of the students who were taught in "1:1"environment. The answers to each question are shown with a specific color - there are 8 different colors for the 8 questions.

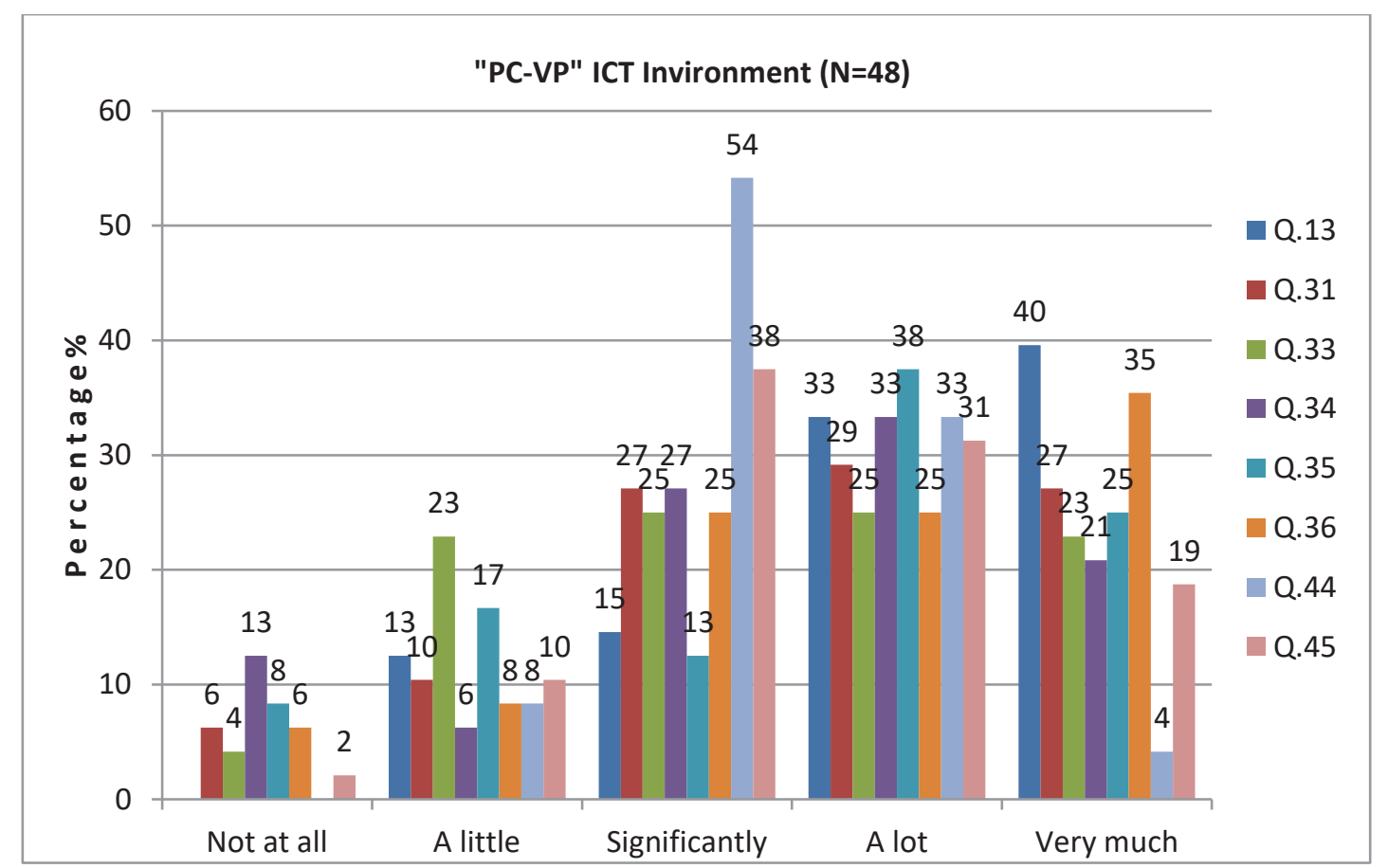

Figure 1: Results from «PC-VP» environment

"Figure 1" shows that, in a "PC-VP" environment, all the benefits concerning the specific eight questions, reached the students to a great extent (Significantly, A lot, and Very much). If the answers to "Significantly", "A lot" and "Very much" are added together, then the percentage of students who - at a great extent - receive a specific ICT benefit, in the "PC-VP" environment, are as follows:

- $88 \%$ of students said that the ICT integration contributed significantly to a better understanding of the lesson (Q.13)

- $83 \%$ of students said that the ICT integration contributed significantly to making the lesson more interesting because it now contains multimedia material (videos, simulations and virtual experiments) (Q.31)

- $73 \%$ of the students said that the ICT integration contributed significantly to the increase of their participation (Q.33) 
- $81 \%$ of the students said that the ICT integration significantly increased the connection of the course (Physics) with real life (Q.34)

- $76 \%$ of students said that the ICT integration significantly increased the opportunities for inquiry (Q.35)

- $85 \%$ of students said that the ICT integration significantly increased the opportunities for student collaboration (Q.36)

- $91 \%$ of students said that the ICT integration significantly increased the opportunities for participating in "variable control" practices when working with experiments (Q.44)

- $88 \%$ of students said that the ICT integration provided more opportunities for doing experiments in ideal conditions, not possible in the school laboratory (Q.45)

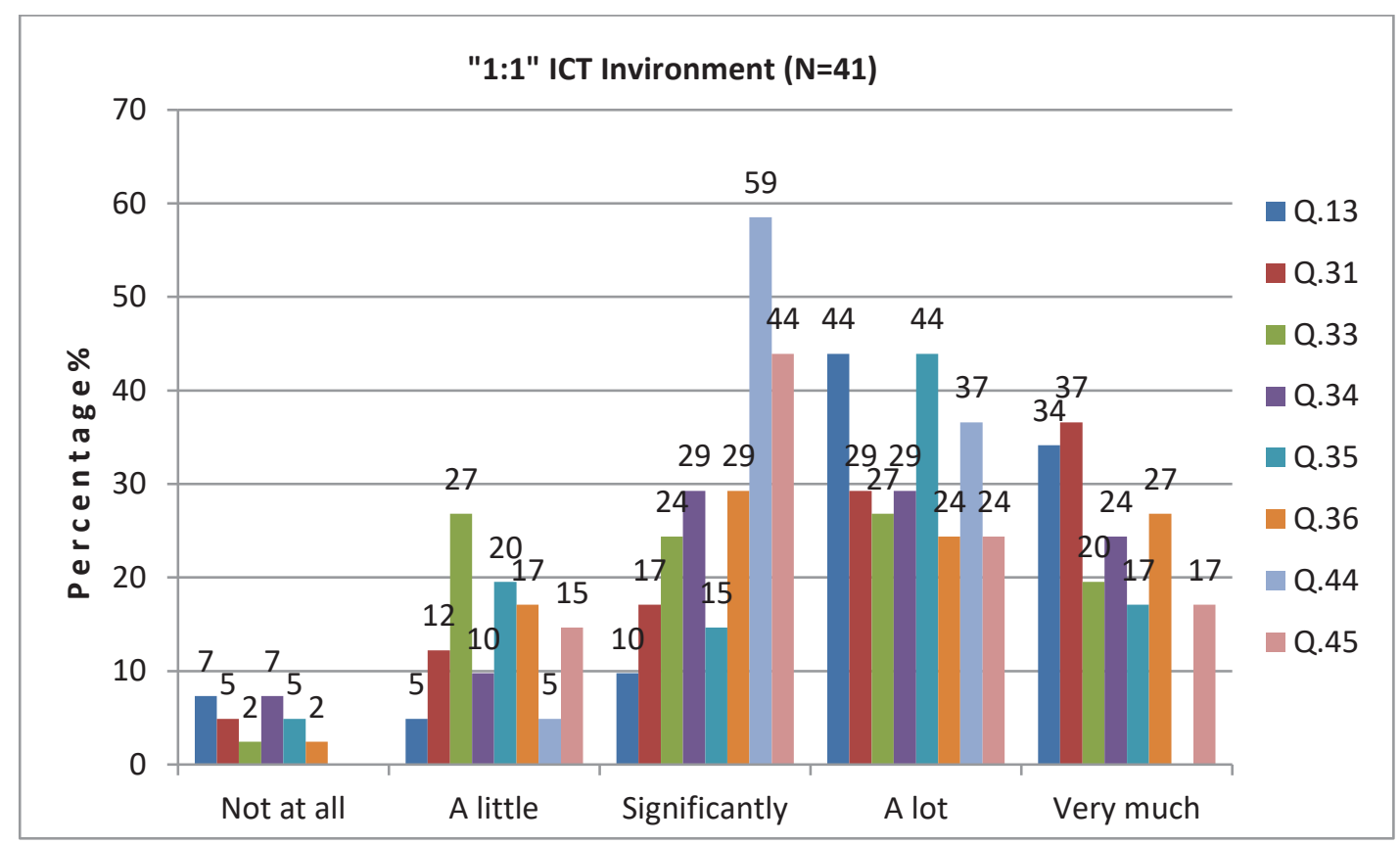

Figure 2: Results from "1:1" environment

"Figure 2" shows that, in a "1:1" environment, all the benefits concerning the specific eight questions, reached the students to a great extent (Significantly, A lot, and Very much). If the answers to "Significantly", "A lot" and "Very much" are added together, then the percentage of students who - at a great extent - receive a specific ICT benefit, in the "1:1" environment, are as follows:

- $88 \%$ of students said that the ICT integration contributed significantly to a better understanding of the lesson (Q.13)

- $83 \%$ of students said that the ICT integration contributed significantly to making the lesson more interesting because it now contains multimedia material (videos, simulations and virtual experiments) (Q.31)

- $71 \%$ of the students said that the ICT integration contributed significantly to the increase of their participation (Q.33)

- $82 \%$ of the students said that the ICT integration significantly increased the connection of the course (Physics) with real life (Q.34)

- $76 \%$ of students said that the ICT integration significantly increased the opportunities for inquiry (Q.35)

- $80 \%$ of students said that the ICT integration significantly increased the opportunities for student collaboration (Q.36)

- $96 \%$ of students said that the ICT integration significantly increased the opportunities for participating in "variable control" practices when working with experiments (Q.44)

- $85 \%$ of students said that the ICT integration provided more opportunities for doing experiments in ideal conditions, not possible in the school laboratory (Q.45)

What follows is the comparison of the statistical distributions of student answers for the two different ICT infrastructure environments ("PC-VP" and "1:1") with the non-parametric test "Man-Whitney U Test ". That is, a comparison between the answers of classes C-3gym-2013 and C-3gym-2012 that were taught respectively in 
those two environments. The answers for each specific question are separately compared. The results of those comparisons are shown in "Table 3".

Table 3: Statistic comparisons \& measures of student answers for "PC-VP" and " $1: 1$ " environments

\begin{tabular}{|c|c|c|c|}
\hline Question & $\begin{array}{c}\text { Compairing: } \\
\text { «H/Y-BП» } \\
\& \\
\text { «1:1» } \\
\text { Z / Sig }\end{array}$ & $\begin{array}{c}\text { Means: } \\
\text { C-3gym-2013 } \\
\text { / } \\
\text { C-3gym-2012 }\end{array}$ & $\begin{array}{l}\text { St. Deviations } \\
\text { C-3gym-2013 } \\
\text { / } \\
\text { C-3gym-2012 }\end{array}$ \\
\hline $\begin{array}{l}\text { Q.13: To what extent do you agree with the sentence } \\
\text { "Now I understand the lesson better"? }\end{array}$ & 0,201 / 0,841 & $4,00 / 3,93$ & $1,031 / 1,149$ \\
\hline $\begin{array}{l}\text { Q.31: To what extent did the lesson become more } \\
\text { interesting because it contains multimedia material } \\
\text { (videos, simulations and virtual experiments)? }\end{array}$ & 0,908 / 0,364 & $3,60 / 3,80$ & $1,180 / 1,209$ \\
\hline $\begin{array}{l}\text { Q.33: To what extent did the use of ICT increase your } \\
\text { engagement/participation in class? }\end{array}$ & $0,250 / \mathbf{0 , 8 0 3}$ & $3,40 / 3,34$ & $1,198 / 1,153$ \\
\hline $\begin{array}{l}\text { Q.34: To what extent do you think the use of ICT linked } \\
\text { Physics to real life? }\end{array}$ & 0,264 / $\mathbf{0 , 7 9 2}$ & $3,44 / 3,54$ & $1,253 / 1,185$ \\
\hline $\begin{array}{l}\text { Q.35: To what extent did the use of ICT provide more } \\
\text { opportunities for inquiry and reflection? }\end{array}$ & $0,396 / \mathbf{0 , 6 9 2}$ & $3,54 / 3,49$ & $1,271 / 1,143$ \\
\hline $\begin{array}{l}\text { Q.36: To what extent do you think the use of ICT } \\
\text { provided more opportunities for collaboration in class? }\end{array}$ & 0,912 / $\mathbf{0 , 3 6 2}$ & $3,75 / 3,56$ & $1,212 / 1,141$ \\
\hline $\begin{array}{l}\text { Q.44: To what extent do you think the use of ICT } \\
\text { provided more opportunities to check the effect of } \\
\text { variables when working with multivariable } \\
\text { experiments? }\end{array}$ & 0,019 / 0,362 & $3,33 / 3,32$ & $0,694 / 0,567$ \\
\hline $\begin{array}{l}\text { Q.45: To what extent do you think the use of ICT } \\
\text { provided more opportunities to perform experiments in } \\
\text { conditions not possible in the school laboratory? }\end{array}$ & $-0,636 / \mathbf{0 , 5 2 5}$ & $3,54 / 3,44$ & $0,988 / 0,950$ \\
\hline
\end{tabular}

Judging from the Sig values (>> 0.05) in Table 3, we can say that at "95\% confidence level" ( $p>0.05)$, for all eight questions, there is no statistically significant difference in the student answers for the two ICT infrastructure environments ("PC-VP" and "1:1").

\section{Discussion}

The results shown in the diagrams (Figures 1 and 2) show that, in both ICT environments under consideration ("PC-VP" and "1:1") the majority of students said that they received all the ICT benefits which correspond to the eight (8) questions asked. More specifically, in a "PC-VP" environment, the percentage of students who said they received the ICT benefits range from 71 to $93 \%$ depending on the benefit, while in the "1:1" environment the range is from 71 to $95 \%$. However, these benefits are the seven of the eight benefits that the ICT can offer to Science teaching. Therefore, the first conclusion that emerges is that the ICT integration - in the way it was done - was largely effective in both ICT environments under consideration ("PC-VP" and "1:1") and what remains to be seen is whether the level of ICT infrastructure available in the classroom affects the degree to which these benefits reach the students.

The answer to that question comes from the comparison of the statistical distributions of student answers in the two different ICT infrastructure environments ("PC-VP" and "1:1"). As shown in Table 3, there is no statistically significant difference in student answers for the two ICT environments under consideration ("PCVP" and "1:1") for any of the questions. In other words, the degree to which students receive the ICT benefits is the same for those two environments. This means that the ICT integration is equally effective and beneficial regardless of the number of the computers in the classroom. However, we should have in mind that this happens when the specific teaching approach (or practice) is used and that different use of technology might produce different results. The results are consistent with the reports of Cuban (2006) and Hu (2007), according to which the introduction of 1:1 environments in US schools did not result in measurable benefits compared to PC-VP environments. Similarly, several other studies show that for teachers, the ICT infrastructure is not an 
important criterion for ICT integration in their teaching practice (Flores, Santero and Gordillo, 2017; Totter, Stütz and Grote, 2006).

The finding, that the teaching approach implemented was largely effective for ICT integration into both ICT environments, is particularly important for those looking for ways to integrate ICT into elementary ICT infrastructure environments such as the "PC-VP" environment. This approach could be applied today in all classrooms equipped with a computer-video projector system. This equipment is already available in several classrooms in the secondary education Greek public schools and it is reasonable to expect that all classrooms will be supplied with this basic infrastructure in the near future. In contrast, providing computers for every student in the classroom is a project which requires more funds and - as far as it concerns the Greek schools it is unlikely to be implemented in the next few years. The importance of this approach is that in Greece, several teachers can use it today in the existing PC-VP classrooms and in the years to come all teachers will be able to use it either in PC-VP or in 1:1 classrooms. It is worth mentioning that the teacher who participated in this survey and who has been lucky enough to teach in PC-VP classrooms since then, has continuously been using the same teaching approach since then (since 2013). She insists she is "very happy with it" and also "feels" her teaching integrates ICT effectively.

The finding, that the level of ICT infrastructure does not significantly affect the benefits of the ICT integration, contradicts our initial prediction - according to which - having many computers would result in more benefits for the students. We would for example expect that more computers would make the lesson more interesting and enjoyable and would increase student participation. In other words, we would expect students to "vote" more for the 1:1 environment and say the lesson was "better" when they had their own computers in class. However, this is not what our results show and the question is "why didn't they". A possible explanation is that while the ICT integration doesn't make a difference when the specific teaching approach is used it might make a difference when different teaching approaches will be used. For example, if the lesson is designed on a more student-centered basis, where every student was expected to work autonomously on his computer and create his own work, then the 1:1 environment will be a necessity and students will probably "vote" for it. Similarly, when the teaching scenario requires the use of the web on a personal or team basis - a scenario possible only in 1:1 environment - students may find this environment more "attractive". In other words, different teaching planning could make better use of what the ICT can offer to students. Some other factors that could explain the students' responses may be the inconvenience of bringing and carrying their computers to school every day, or the technical computer (software or hardware) problems that often occurred during class, causing frequent lesson interruptions. These interruptions often broke the normal flow of teaching because the teacher, in the absence of technical support, had to take care of such problems. Finally, the school or student culture might be a factor affecting student answers (the results). That is, the way students used to learn in the particular school or in the educational system of Greece, might be such a factor. From our experience, the traditional teacher-centered teaching seems to be the norm in the Greek schools. If students are used to this kind of teaching, they may feel more comfortable and see more favorably a PC-VP environment in comparison to a 1:1 environment. Despite the above possible explanations and the limitations on the drawn conclusions, the results still show equal benefits for the two ICT environments examined.

An important question that arises is which investment is preferable on a "value for money" basis. Investing in "PC-VP" or "1:1" ICT environments? For those countries or school districts which can easily afford the "1:1" ICT environment, this environment is probably a better choice since it can be considered an investment for the future as it can be used by teachers who can benefit further from the additional possibilities the 1:1 environment can offer. It allows for more autonomous student work and might be more effective when different teaching approaches are used. For those with limited budgets, as is the case for Greece, it might be better to go step by step and first equip all classrooms with a computer-video projector system leaving the 1:1 environments for the future. In any case, given that today most Greek schools lack the basic ICT infrastructure (PC-VP) and no ICT integration can happen in those schools, it is imperative to install PC-VP infrastructure in all classrooms without any delay. The results of this study are an additional argument for making that choice.

We need to keep in mind that the only source of data is the student answers. More data and more data sources would further support the conclusions drawn. When 1:1 environments appear in some public schools or some classrooms, more data could be produced from bigger samples and from different age classes. This is expected to happen in the next couple of years through the European Union programs expected to run in the 
next few year. A survey of the teachers' opinions on the matter would be another source of data. Again, in the coming years, when 1:1 environments exist in several schools, then teachers' opinions can be studied.

\section{Conclusions}

In the present study, the degree to which the level of technological infrastructure can affect the ICT benefits in the daily science teaching was investigated. The ICT integration was attempted through a specific teaching approach which uses digital work sheets with specific characteristics.

The results show that, when the specific teaching approach is used, the benefits the ICT can offer to sciences teaching reach students at the same degree in a teaching environment where there is only a PC and a video projector and in a teaching environment where every student has his own computer.

Based on the results of the research and taking into account the current economic situation of Greece, it is important to ask ourselves if at the present time it is preferable to invest in 1:1 or in PC-VP infrastructure for public school classrooms. The results show that unless different teaching approaches are used, investing in 1:1 environments does not secure additional benefits. We should also have in mind that "different teaching approaches" require teachers able to effectively implement them. Different approaches might benefit further from the additional possibilities the 1:1 environment can offer. For example, more student-centered approaches requiring more autonomous student or team work might make the difference in this environment. In addition, if the 1:1 infrastructure is chosen, besides the computers cost, we should also take into account the cost of maintenance, technical support and storage of the computers. Other ideas for solving the infrastructure problem, like the "BYOD" initiative, cannot be adopted in Greece because - according to the current legislation - no personal student portable devices are allowed in the classroom. However, this might be a solution for countries where such legislation is not in effect. On the other hand, it will not be reasonable to support the idea of not advancing the ICT infrastructure beyond the PC-VP level. Advances in ICT, the use of portable devices (smartphones etc.) in the classroom, and the development of new powerful science applications which can promote inquiry-based learning and communication will lead to classrooms where everybody will have to have his own "computer", and this is going to be the future for the Greek public schools classrooms.

The specific teaching approach used in this study, achieved satisfactory ICT integration in both ICT environments considered here. This means that the secondary education teachers who teach science in public high school PC-VP classrooms can use it without waiting for any major coming improvements in the ICT infrastructure. It also makes sense for school administrators and teachers to ask for PC-VP infrastructure to be installed in every classroom if any ICT integration in teaching is to happen. It will be a wise move, will not cost much and may immediately bring considerable benefits to teaching and learning. . Beyond this, we wish and hope the Greek Ministry of Education will be able - in the Greek school classrooms - to upgrade the ICT infrastructure to 1:1 level or even further so that teachers and student will be able to benefit in all possible ways ICT can benefit teaching and learning.

In this study, the "samples" used for statistical analysis were relatively small (N1 = 48, for PC-VP and N2 $=41$ for 1:1 environment). More research is needed to draw safer conclusions. More research could be done using larger samples (more student participants), on other science subjects or based on teachers' views. It would be interesting to apply the same approach with students of different age (grade). More data and more queries can further support the results.

\section{References}

Bariu, T. N. 2020., Status of ICT infrastructure used in teaching and learning in secondary schools in Meru County, Kenya. European Journal of Interactive Multimedia and Education, 1(1), e02002. https://doi.org/10.30935/ejimed/8283

Bebell, D., 2005. Technology promoting student excellence: An investigation of the first year of 1:1 computing in New Hampshire Middle Schools. [pdf] Available at:

$<$ https://www.researchgate.net/publication/28798429_Technology_Promoting_Student_Excellence_An_Investigatio n_of_the_First_Year_of_11_Computing_in_New_Hampshire_Middle_Schools> [Accessed 15 October 2020].

Cuban, L., 2006. The laptop revolution has no clothes [online] Available at: <http://www.edweek.org/ew/articles/2006/10/18/08cuban.h26.html?print=1\&print=1> [Accessed 29 April 2020]. 
Drayton, B., Falk, J., Stroud, R., Hobbs, K., and Hammerman, J., 2010. After installation: ubiquitous computing and high school science in three experienced, high technology schools. Journal of Technology, Learning, and Assessment, 9(3), pp.4-56.

Dunleavy, M. and Heinecke, W.F., 2007. The impact of 1:1 laptop use on middle school math and science standardized test scores. Computers in the Schools, 24(3/4), pp.7-22.

European Commission, 2019. Shaping Europe's digital future, 2nd Survey of Schools: ICT in Education - Objective 2: Model for a "highly equipped and connected classroom". [online] Available at: <https://ec.europa.eu/digital-singlemarket/en/news/2nd-survey-schools-ict-education> [Accessed 15 April 2020].

Flores, J., Santero, J. and Gordillo, J.J., 2017. Factors that explain the use of ICT in secondary-education classrooms: the role of teacher characteristics and school infrastructure. Computers in Human Behavior, 68, pp. 441-449. https://doi.org/10.1016/j.chb.2016.11.057

Gulek, J.C. and Demirtas, H., 2005. Learning with technology: the impact of laptop use on student achievement. Journal of Technology, Learning, and Assessment, 3(2), pp. 1-38. [pdf]. Available at: $<$ https://ejournals.bc.edu/index.php/itla/article/view/1655> [Accessed 15 November 2020].

Karal, H., Bahçekapılı, T. and Reisoglu, I., 2009. Usability of testing apparatuses about renewable energy resources in constructivist class environment. Procedia Social and Behavioral Sciences, 1(1) pp.1264-1271.

Hennessy S., Deaney R. and Ruthven K., 2004. Technology-integrated science teaching: Exploiting opportunities and adapting to constraints. [DOC] Available at: http://www.educ.cam.ac.uk/research/projects/istl/ScT2.doc [Accessed 15 November 2020].

Hew, K., and Brush, T., 2007. Integrating technology into K-12 teaching and learning: current knowledge gaps and recommendations for future research. Educational Technology Research and Development, 55(3), pp.223-252.

$\mathrm{Hu}, \mathrm{W} ., 2007$. Seeing no progress, some schools drop laptops. [online] Available at: <http://www.nytimes.com/2007/05/04/education/04laptop.html?pagewanted=all\& $r=0>$ [Accessed 29 April 2020].

Hyunjin, C., Taejung, P., and Jongwon, S., 2020. What should be considered when developing ICT-integrated classroom models for a developing country? Sustainability 2020, 12(7), pp.2967. https://doi.org/10.3390/su12072967

Lu, C., Tsai, C. and Wu, D., 2015. The role of ICT infrastructure in its application to classrooms: a large scale survey for middle and primary schools in China. Educational Technology \& Society, 18 (2), pp.249-261.

National Research Council, 2012. A framework for K-12 science education: practices, crosscutting concepts, and core ideas. Washington, DC: The National Academies Press. https://doi.org/10.17226/13165.

Norris, C. and Elliot S., 2010. One-to-one computing has failed our expectations [online] Available at: $<$ http://joomla.webstercity.k12.ia.us/phocadownload/administration/principal/One\%20to\%200ne\%20Computing\%20Has\%20Failed\%20Our \%20Expectations.pdf> [Accessed 15 October 2020].

Olsen, D., 1999. Constructivist principles of learning and teaching methods. Education, 120 (2), pp.347.

Osborne, J. and Hennessy, S., 2003. Literature review in science education and the role of ICT: Promise, problems and future directions. [pdf] Available at: <https://www.nfer.ac.uk/publications/futl74/futl74.pdf> [Accessed 15 October 2020].

Penuel, W.R., 2006. Implementation and effects of one-to-one computing initiatives: a research synthesis. Journal of Research on Technology in Education, 38(3), pp. 329-348.

Baviskar, N.S., Hartle, R.T. and Whitney, T., 2009. Essential criteria to characterize constructivist teaching: derived from a review of the literature and applied to five constructivist-teaching method articles, International Journal of Science Education, 31(4), pp.541-550. DOI: 10.1080/09500690701731121

Sauers, N. J. and Scott M., 2012. What does the research say about school one-to-one computing initiatives? [pdf] Available at:

https://static1.squarespace.com/static/528fd1d3e4b023ca755e1561/t/52dd5881e4b083346078cfbc/139023782592 6/CASTLEBrief01 LaptopPrograms.pdf [Accessed 15 October 2020].

Smallhorn, M., Young, J., Hunter, N. and Burke da Silva, K., 2015. Inquiry-based learning to improve student engagement in a large first year topic. Student Success, 6(2), 65-71. doi: 10.5204/ssj.v6i2.292

Stanbury, M., 2010. One-to-one computing programs only as effective as their teachers. [online] Available at: <http://www.eschoolnews.com/2010/02/16/11-programs-only-as-good-as-their-teachers/> [Accessed 15 October 2020].

Totter, A., Stütz, D. and Grote, G., 2006. ICT and schools: Identification of factors influencing the use of new media in vocational training schools. The Electronic Journal of e-Learning Volume 4(1), pp 95-102. Available through www.ejel.org [Accessed 15 October 2020].

Unal, S. and Ozturk H.I., 2012. Barriers to ITC integration into teachers' classroom practices: Lessons from a case study on social studies teachers in Turkey. [pdf] Available at: < https://cutt.ly/Pt7KpAm> [Accessed 16 April 2020].

Voogt, J., Knezek, G., Cox, M., Knezek, D., and Brummelhuis, A., 2013. Under which conditions does ICT have a positive effect on teaching and learning? A call to action. Journal of Computer Assisted Learning, 29(1), pp.4-14. https://doi.org/10.1111/j.1365-2729.2011. 00453.x

Zucker, A.A., McGhee, R., 2005. A study of one-to-one computer use in mathematics and science instruction at the secondary level in Henrico County Public Schools. [pdf] Available at: <http://ateneu.xtec.cat/wikiform/wikiexport/ media/materials/jornades/jt101/bloc1/henrico finalreport.pdf> [Accessed 15 October 2020]. 


\section{References in Greek:}

Platinakis, K., 2011. Factors that discourage high school teachers in using ICT in their teaching. [pdf] Available at: $<$ http://users.sch.gr/platinakis/yliko/tpe/20\%20TPE\%20Patra-platinakis.pdf> [Accessed 15 October 2020>. Tzifopoulos, H. M., 2010. Digital Literacy of pre-service teachers. Thessaloniki: Kyriakidis. 